Monday to Wednesday or Thursday to Saturday. The analysis were carried out for the overall sample and stratified by sex using the Mixed Linear Model and the effect of age and gender was tested.

Results The macronutrient intake varied according the week phase. The analysis of the overall sample showed increasing consumption from the beginning to the end of the week for all macronutrients. However, the increased macronutrient consumption occurred at expenses of women's intake and the difference on intake was $482.64 \mathrm{kcal} /$ day; $\quad \mathrm{p}=0.010 ; \quad 61.16 \mathrm{~g} /$ day; $\quad \mathrm{p}=0.019 ; 11.53 \mathrm{~g} /$ day; $\mathrm{p}=0.014$; and $22.76 \mathrm{~g} / \mathrm{day} ; \mathrm{p}=0.010$; for energy, carbohydrate, protein and total fat, respectively, for the end of the week.

Conclusion These results show that adolescents have increasing consumption of macronutrient during the week, reaching the highest intake at the end of week.

\section{SP3-94 COMMUNITY ASSESSMENT OF SHAHINSHAHR CITY, ISFEHAN, IRAN}

doi:10.1136/jech.2011.1429760.94

K H Naieni, ${ }^{*}$ J Karimi, E Ahmadnejad. School of Public Health, Tehran University of Medical Sciences, Tehran, Iran

Introduction Community involvement is the most important strategy in development. In health program planning, community assessment is a process in which society members get a thorough understanding of all matters and problems. This study was conducted to identify and prioritise problems of the ShahinShahr city, in 2009, with active participation of the people. ShahinShahr is a city with a population of over 150000 located $20 \mathrm{~km}$ to the north of Isfahan, Iran. Community assessment is one of the core competencies for Public Health Professionals and it gives them a better understanding about the strengths and drawbacks of their jurisdiction.

Methods The study was based on our local experiences and a model designed in North Carolina, US. In this model, the assessment process is performed in eight steps in ShahinShahar. In the first seven steps problems are identified and prioritised, and in step 8 a plan of action is developed to deal with the problem selected. The assessment team included wide range of key stakeholders and local people were in three levels: Advisory, work and project group. Observation, interview, focus group discussion and summary list of health resources used for data collection.

Results More than 50 problems were identified, of which the following were considered to be top priorities: drug abuse, smoking among adults and depression. After creating community assessment profile, community health action plans were provided.

Conclusion The neglected community assessment is one the best tool for assessing communities to identified and prioritised health problems in developing countries.

\section{Global health}

SP4-1 INTERACTION BETWEEN SUBJECTIVE AND OBJECTIVE
OCCUPATIONAL CONDITIONS IN AFFECTING PHYSICAL
HEALTH OF WOMEN WORKERS IN MULTINATIONAL
ESTABLISHMENTS

doi:10.1136/jech.2011.1429760.95

S F Lu, ${ }^{*} \mathrm{~J}$ L Lu. National Institutes of Health, University of the Philippines Manila, Manila, The Philippines

The Philippines has established many export zones as a response to the Structural Adjustment Programs of the World Bank in order to stabilise its economy. The study aimed at looking into the problems caused by organisational factors such as job autonomy, content of job, nature of task, hazard exposure and management styles to mental health of women workers. This was conducted in an export zone involving 31 industries and an interview with 613 women workers. The results showed that there were several interactions between variables which include the following- the need for new quality for products is associated with the need to upgrade knowledge and skills, fast-pace work is associated with heavy physical load, poor health and safety policies at work with exposure to vapours, and participation in benchmarking with better policies on promotion and training. Other significant associations were: exposure to vibration with noise, and awkward positions while working and prolonged standing in the workplace. Correlation matrix was also done for the factorised variables in the worker's questionnaire. The significant associations show the following statistical conclusions. Boring and repetitive jobs and work pressure were correlated with absence of programs other than health and safety while sufficient salary and compensation was correlated with the presence of such programs. Workers who have no autonomy in applying their own strategy to accomplish their work are likely to have low mental health. Workers also tend to have low mental health when they are subjected to close monitoring, hazardous work pressure and, poor work quality. Medium industries are less likely to have cases of low mental health among workers. This study has policy implication and can serve as a basis for advocacy work and program implementation for the promotion of mental health counselling.

\section{SP4-2 ASSOCIATION BETWEEN HYPERGLYCEMIA AND GLYCATED HAEMOGLOBIN}

doi:10.1136/jech.2011.1429760.96

T Dzebisasvili.. Moscow Regional Research Clinical Institute, Moscow, Russia

Aim To assess association of blood glucose levels and haemoglobin A1c.

Materials and Methods Population-based screening for glucose metabolism impairments using standard 2-h OGTT among 661 adults in Moscow Country was conducted in 2009. HbA1c was determined in 39 subjects with glucose metabolism impairments. Correlation ( $\mathrm{r}$ ) and unstandardised regression coefficient (B) was calculated.

Results There was no association ( $r=0.306, p=0.083$ ) between fasting hyperglycemia and $\mathrm{HbA} 1 \mathrm{c}$ in people without T2DM, also there was no association $(r=0.134, p=0.456)$ between 2 - $h$ hyperglycemia and HbA1c in people without T2DM, but there was positive association between IFG+IGT and HbA1c $(B=3.180$, $\mathrm{p}=0.024)$. Also newly diagnosed T2DM increase HbA1c $(B=1.735$, $\mathrm{p}=0.031$ ).

Conclusion Only combination IFG+IGT and T2DM increase HbA1c

\section{SP4-3 THE POSSIBILITIES OF THE SYMPTOM THROUGH THE CONTINUE USAGE OF WIRELESS COMMUNICATING DEVICES AMONG THE POPULATION}

doi:10.1136/jech.2011.1429760.97

${ }^{1} \mathrm{~N}$ Kumar, ${ }^{*} \mathrm{~V}$ P Sharma, ${ }^{1} \mathrm{R}$ A Khan. ${ }^{1}$ Babasaheb Bhimrao Ambedkar University (Central University), Lucknow, Uttar pradesh, India; ${ }^{2}$ Indian Institute of Toxicology Research, Lucknow, Uttar pradesh, India

The human brain and the way in which it stores and retrieves information is a subject of debate and speculation. There are many possible causes of memory loss or forgetfulness; some factors may be like tiredness, concentration problem, pregnancy, general anxiety, normal ageing and more serious causes are Alzheimer's disease, 